\title{
THE LINGUISTIC CONSTRUCTION OF ASSOCIATIVE PERSONAL LABELIZATION OF FACEBOOKERS' NICKS
}

\author{
${ }^{\text {a }}$ Iqbal Nurul Azhar, ${ }^{\mathrm{b}}$ Darul Hikmah \\ ${ }_{a, b}$ Universitas Trunojoyo Madura \\ e-mail: iqbalnurulazhar@yahoo.com
}

\begin{abstract}
This study investigates nicks (nicknames) of Facebook users (Facebookers). It specifically reveals the process of how Facebookers associate themselves with their nicknames and with all things around them. This study also finds out the factors that contribute to the choice of Facebookers to use their nicknames. This study uses sociolinguistic to approach the data. The data were obtained by using content analysis method. The data analysis method used to analyze the data was the Correlation Method with referents as the determining elements. The result of the study shows that there are personal identities associated to the nicknames used by Facebook users. It also shows that the uses of the nicknames by the Facebook users are influenced by their personal fancies (personal labelization). Besides, there are fifteen factors contributing to the choices of nicks (nicknames) by Facebook users, five major reasons that caused the informants to create the unique nicks and three issues which can be summarized related to personal autolabelization phenomena.
\end{abstract}

Keywords: Social Identity, Nicknames, and Personal Labelization. 


\section{INTRODUCTION}

Human living in this social world is always tied up to iidentity. The identity is not only a matter of how human thinks but also how human plays roles in society. Everyone will have their own way to think and they will have their own way to act or behave in the society. Such thing will be found in social interaction where people or groups of people communicate one another. In this case, a process of self-recognition which further becomes social identity will exist as well.

An identity can be understood as a person who has distinguishing features (both physical and experience, such as one's personal life cycle), as well as components related to one's role in social groups where social interactions occur. Additionally, an identity can also be defined as a character that is an attribute (nickname, title, character, ect) of an individual or community group. These identity characteristics can be attached to the body, such as gender or ethnicity, or a life track record such as our chosen education or political affiliation. Thus, the size of our perspective to assess ourselves and see our role in a social environment can affect the way we behave, on the things we will believe in, and on which groups we will rely on and be affiliated with.

In addition, people's identity can be recognized and identified through their social interaction. In the status quo social interaction, how one interacts with others, can easily be found in online community. The processes of self-identification have very visible patterns in online technology world (the internet). In online technology, cyber devices have the potential to help people identify and form an identity. There are various complex identification processes which occur simultaneously in these realms, such as social networking sites (facebook, twitter, instagram, etc.), chat rooms, or discussion groups. Identity markers, such as gender, age, nickname, physical character, are frequently shown in these cyberspaces. The thing making it complicated is that sometimes these identity markers, whether intentionally or unintentionally, by an individual or group of people are covered by a "mask" in the name of human's right. These markers are often preserved from being shown to public through incipient semiotics process. These sometimes cause misunderstanding, negative prejudices, and even threats among people.

In other online world contexts, by typing certain information on a keyboard, such an identity will immediately exist (Sundén, 2003). From this context it can be seen how powerful people are because they can, with their own hands, "create and give birth" to an individual identity. Not only creating and giving birth, today, people are also able to determine their physical and psychological characteristics, create personalities as they wish, and leave traces of clearly visible histories that can be captured, tracked, packaged, and shared with other individuals in cyberspace.

One of the cyberspaces (online worlds) where individual identity can be found is Facebook. The use of Facebook has increased in recent years. Initially the users were young people, but now, Facebook is used by almost all members of global human demography. This social media allows users to create, share, consume, and collaborate with various contents for the purpose of communicating, recommending and offering something, persuading, remixing, and sharing texts, videos or images.

Facebook contains a complete package that can be a social driving force because it has the potential to influence the identity of individuals or groups and can help the individuals or groups see themselves and others. This encouragement also includes the desire to be selectively involved in self-representational activities, awareness to introduce a large number of identities in online settings carried out simultaneously to 
many people, as well as the desire for various social data in the form of current issues, and identity calculations. This can be identified through Facebook's ability to track the behavior of its users revealing their identity.

One of the consequences above is the emergence of questions "can we be whatever we want in the online world?" "What distinguishes online identity images from offline?" "To what extent can or cannot individuals share identities and contrasting identity in the online world?" "What are the consequences of doing so much social interaction in the online world?" The above questions have prompted many academicians to conduct observations regarding this issue. Some of them are Acquisti, Gross, and Stutzman (2011), Boyd (2010 and 2011), Boyd, Hargittai, Schultz, and Palfrey, (2011), De Koster and Houtman (2008), Ellison, Heino, and Gibbs (2006), Ellison, Hancock and Toma (2012), Lev and Lewinsky (2004), Nakamura, (1999), Scheidt (2001), Ashirova et.al (2016), Gonibeed (2014), Starks (--), and many others.

Some studies about Facebook that intersect with identity problems can also be traced, such as those conducted by Ellison, Steinfield, and Lampe, (2007 and 2011), Gonzales and Hancock (2011), Phillips (2011), Reisinger (2012), and Vitak, Lampe, Gray, and Ellison (2012). Unfortunately, even though the identity topic has often been studied and revealed in public, and the identity of a persona can be classified as "public," they seem to have been ignored in linguistic research. This can be seen from the limited number of comprehensive studies about identity through linguistics perspective. Most of them are still in the area of communications or governances, or laws and social norms. As far as the writers' know, these studies have not been strongly related to the linguistics domain. On the basis of this gap of study, this article is presented.

In relation to those things, this article explicates specifically the process of how Facebookers associate themselves through their nicks (nicknames) with the thing that are around them, as well as the factors that contribute to the selection of Facebookers' nicks. Furthermore, the reasons for using nicks, the factors that motivate someone who uses a nick or nicks and the conclusions of values (cultural values) would be discussed here.

\section{METHOD}

This study applied sociolinguistics to approach the data. The data of this study were obtained through content analysis method. The data analysis method used to analyze the data was the Correlation Method. Correlation Method is a method used to determine the identity of determinant linguistic units by correlating them to some external key factors, outside of language, regardless of language, and are not part of the language being studied. The key factors of this study are the referents being referred by the nicks.

This study limited the data to the nicks of Facebook users (Facebookers) who are the members of some overseas Facebook groups of teenage, such as "World Class Dating Group", "American Show Racer FB Group", "Professional Traveler", "Elite Meeting," etc. The groups were selected because the groups were open groups. Their members had various social backgrounds. Their members also demonstrated dynamic social interactions. Due to the large number of the Facebook group members, only those 100 unique nicks were chosen as the data. They were chosen in random, but they were still limited by considering the gender and age (i.e. purposive random sampling). 


\section{FINDING AND DISCUSSION}

\section{THE ASSOCIATION PATTERNS OF AUTO-LABELIZED IDENTITIES}

The use of Facebook as social media has increased in the last few years. Huge number of people has Facebook account and uses it as a media to communicate to others in an online way. Seen from the characteristics of its users' activities, Facebook can be described as social media which is characterized by: 1) building images for public identity that the user wants in a limited system (only in the virtual world and only in Facebook), 2) managing them personally by registering and inviting friends or the people who they think they can share with, 3) showing relationships between users whether friends, good friends or just acquaintances, 4) consuming, producing, and / or interacting with the information created by themselves or by others who are friends, 5) enjoying entertainment facilities because Facebook offers a lot of online games that are connected with.

In general, the user's identity can be tracked well by looking at the lingual nick units in the Facebook. Through randomly chosen nicks that become the data of this study, a vast amount of information regarding how group members play around with their identities in cyberspace is revealed. From the data obtained in the study, personal identities auto-labeled by or associated with the Facebookers' nicks can be summarized as follow:

Table 1. Patterns of Associations of Auto-labelized Identity

\begin{tabular}{|c|c|c|}
\hline No & Associative Identities & $\begin{array}{c}\text { Frequency of } \\
\text { Appearance }\end{array}$ \\
\hline 1 & Autolabelization associated with fictional characters & 23 \\
\hline 2 & Autolabelization associated with places of origin & 16 \\
\hline 3 & Autolabelization associated with idols & 11 \\
\hline 4 & Autolabelization associated with symbol of kindness & 8 \\
\hline 5 & Autolabelization associated with feelings & 7 \\
\hline 6 & Autolabelization associated with animals & 7 \\
\hline 7 & Autolabelization associated with time of existence & 5 \\
\hline 8 & Autolabelization associated with nobility & 5 \\
\hline 9 & Autolabelization associated with instruments & 5 \\
\hline 10 & Autolabelization associated with religions & 4 \\
\hline 11 & Autolabelization associated with physical appearances & 3 \\
\hline 12 & Autolabelization associated with occupations & 3 \\
\hline 13 & Autolabelization associated with ideology & 1 \\
\hline 14 & Autolabelization associated with personal relation & 1 \\
\hline 15 & Autolabelization associated with sex and eroticism & 1 \\
\hline & $\begin{array}{l}\text { TOTAL DATA } \\
\end{array}$ & 100 \\
\hline
\end{tabular}

Based on the results of the study listed in the previous table, it is found that the formation of the nicks of Facebook users (i.e. signifier) does not definitely correlate to the body or real name of person who uses the nick (i.e. referent/ signified). On the other hand, it mostly refers to other things or other people, such as fictional characters, place of origin, idols, beauty, feeling, animals, time, etc. The things or the people that the nicks are associated with are only the fancies and the wishes of the Facebook users. It is not particularly the icons attached to them. They just have the nicks for casual purposes. In other words, most identities that appear in the form of Facebook nicks are due to arbitrary factors; not iconic factors. However, there are certainly some nicks 
that at least still relate to the factual information about the users, such as their place of origin and feeling.

One of autolabelizations which appears in Facebook nicks is associated with fictional characters. This kind of autolabelization is found mostly in female Facebook users' nicks. They use the names of characters in fiction, for they like to characterize themselves with what are attached to the chosen fictional characters. The mostly chosen fictional character is "Barbie". Even though "Barbie" first appeared as an icon of fashion doll, such character in the last decades has become one of the most iconic princess characters in Disney film. This princess is very well known as a beautiful, fashionable, kind, attractive, and charming princess. Surprisingly, "Barbie" is not only used as the nick by child or teenage users, but also by adults. It is probably due to most of females want to look like Barbie with full of marvelous characteristics. The following figures are the samples of Facebookers' nicks using "Barbie":
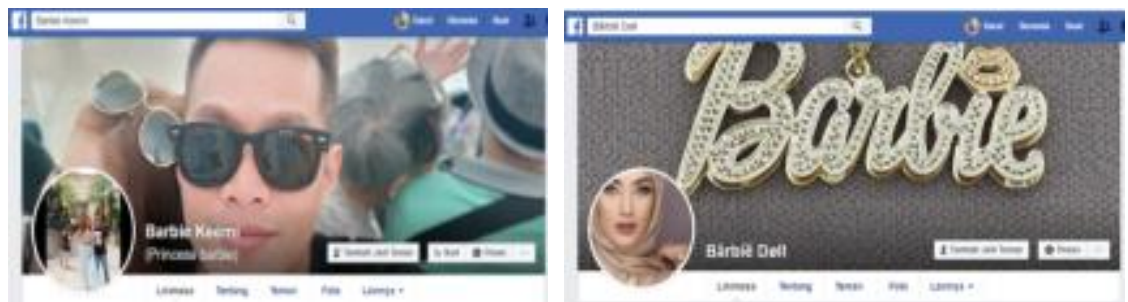

From the figures above, "Barbie Keemi" and "Barbie Doll" are known to be the nicks used by Facebookers. From the fact that all of the users of the nicks are females, the nicks might represent their wish and imagination to be like Barbie, not only in their look but also in how they act and would be treated in society. In other words, they wish to always look stylish, such as beautiful, fashionable, charming, and young. They also wish to act and be treated as public figures who are very popular and respected in the society.

Another autolabelization is associated with some places of origin. This kind of autolabelizations is found both in female or male Facebook users' nicks. By having the nicks, it appears that they try to show to the public where they are from. It probably deals with their national identity, pride of origin, or public recognition. Through Facebook, the users might proudly want to show to the public that their place of origin is nice, rich, full of culture and tradition, and glamorous.
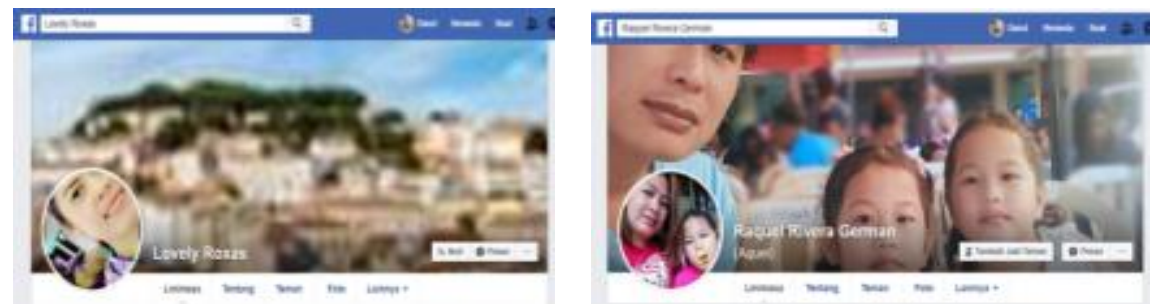

"Lovely Roxas" is an example of the Facebook nicks which is associated with a place of origin. Roxas is a city in Philippines. The city is considered beautiful for its wonderful tourism places and girls. Through this nick, the user might try to show to public that Roxas is really wonderful city. The users would say, "This is me from Roxas and I am a lovely girl from Roxas, and yes I'm definitely proud of Roxas". The second example of nick associated with a place of origin is "Raquel Rivera German". From this nick it is understood that the user is from Germany. The user intends to show 
to the public from which country she is. Hence it is because she is proud of being German resident. Yet Germany is very popular with its large metropolises such as Berlin, and with its capital financial and busiest airport such as Frankfurt. Simply, Germany is a rich country for which the nick user is proud of.

Beside associated with fictional characters and places of origin, another type of autolabelization is also found in the list of data. It is associated with idols. An idol can simply be defined as a figure, commonly public figure or famous person, whom a certain person admires. In this case, the use of idol's names in Facebook nicks becomes very common, especially in the world of teenage. Teenagers mostly like to be recognized by the public for their popular idols. Morover, they also want to imitate the characters of their idols; they want to be as popular as the idols. However, in fact it is not only teenagers who use the names of idols as their Facebook nicks but also the adults. The following figures are the samples of how Facebook users attach their idols' name to their Facebook nicks.
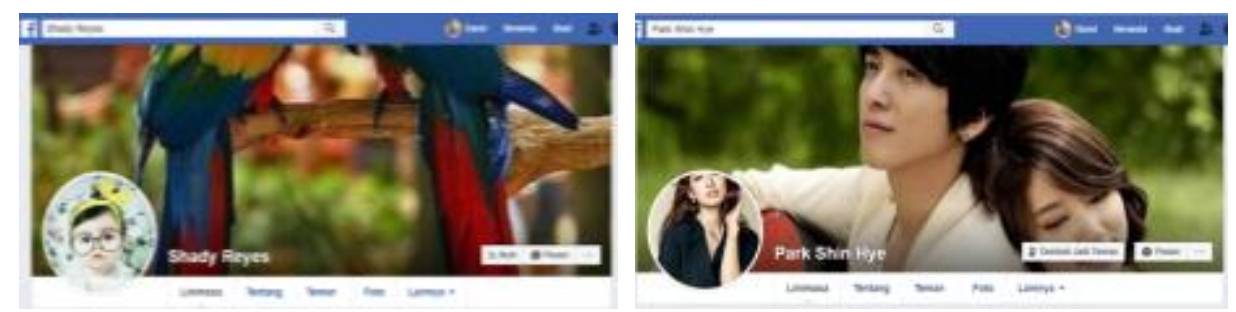

The word 'Reyes' attached to Facebook nick "Shady Reyes", shown in the figures above refers to the name of popular Spain football player, José Antonio Reyes. Before his death, he was one of popular football players. Many people around the world, male and female, become his fans. The Facebooker also wishes to be as popular as that figure, so she uses Reyes's name in line with her name and show them to the public the unification. Similarly, another nick associated with an idol shown above is "Park Shin Hye". Park Shin Hye is one of popular female Korean actresses. She is very popular with her natural beauty. Her popularity has spread widely not only around Asian country but also around the world. The Facebook user, by using Park Shin Hye's name, might wish to be as popular as her.

In some ways, Facebook nicks used by the Facebook users are associated with symbols of kindness. It is indirectly auto-labeled to a kind character. A kindness is always attached to being helpful, wise, and benevolent, etc. By using such nicks, the users might try to show to the public that they are kind, helpful, wise, and benevolent. They try to get their identities through the nicks used in the Facebook. By having such identity - identity of being kind human - the users might wish to be loved by other people in their society. Accordingly, the symbol of kindness often appears with the word 'angel'. 'Angel' literally refers to supernatural being who acts as intermediary between God (or Heaven) and humanity. An angel, in mythological way, also plays role to protect, guide human beings, and carry out task on behalf of God. An angel is believed to be holy creature. Additionally, an angel is naturally characterized with being intelligent, wise, patient, modest but glorious, worthy and beautiful, etc. From those characteristics of angel, as symbol of kindness, Facebook users often use the word 'angel' for their nicks. It can be shown in the following figures. 

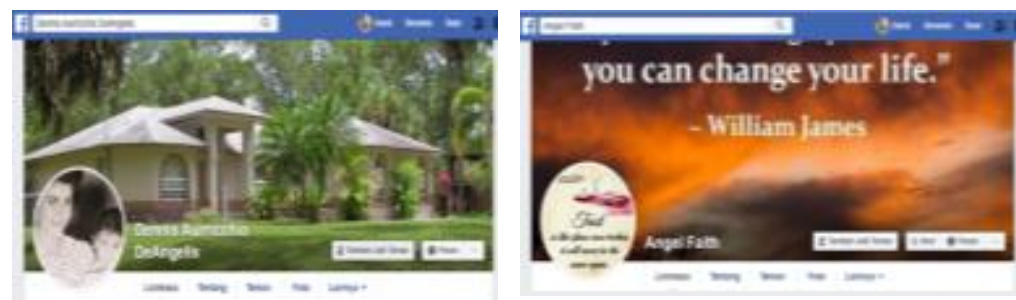

Nicks with the word 'angel' attached to them are mostly used by female Facebook users. In this study, there is not found nick with the word 'angel', used by male Facebook users. "Dennis Aurricchio DeAngelis", and "Angel Faith" are the samples of this type of autolabelization. All of them are female's nicks. Hence, it is because a woman tends to wish and create identity in the society that they could be like angels that are helpful, worthy, glorious, wise, patient, and modest.

A further autolabelization found in this study is associated with feeling. As having mentioned in the introductory part of this article, social media, such as Facebook, can be used to express many things including the feeling of its users. In this case, Facebook users try to express their feeling through the use of nicks. Based on the results of data analysis, it is found that most feeling expressed through Facebook nicks is the feeling of love and being lucky. The expression of feeling of love and being lucky appearing in the Facebook nick are not only expressed by female users but also by males.
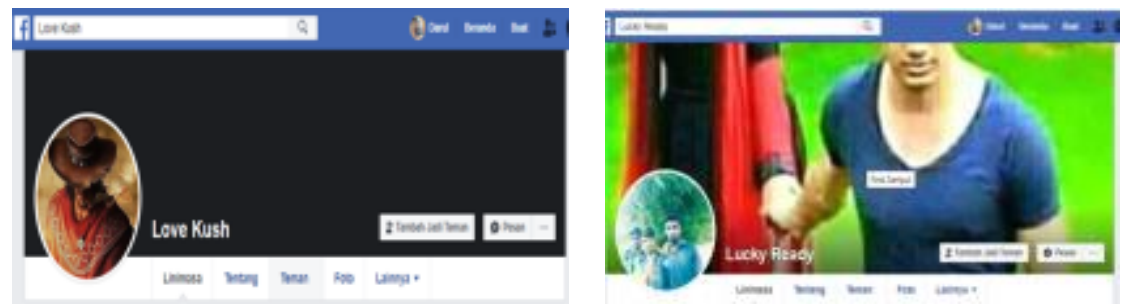

Facebook nick like "Love Kush" depicted in the figure above is associated with the feeling of love. It can be whether the Facebook user wants to show to the public that she loves someone or something, or that she is loved by someone or something. Accordingly, the situation is apparently about love feeling. Beside the feeling of love, another autolabelization found in this study is associated with the feeling of being lucky. "Lucky Ready" is one sample of nicks attached to this kind of feeling. It is probably not only about the feeling of being lucky but also about optimism to always be a lucky person. Thus, by the use of the Facebook nick, the user would create and identity that he is an individual with full luck, and have the right to always be lucky in the society.

In addition, autolabelization associated with animals is also found in this study. Nicks associated with animals are mostly used by male users. Based on the analysis, self-naming through the names of animals might show the wish of the Facebook users to be known as having character like the animals' names being used. The names to be used in this case are "Pigeon" and "Elephant." 

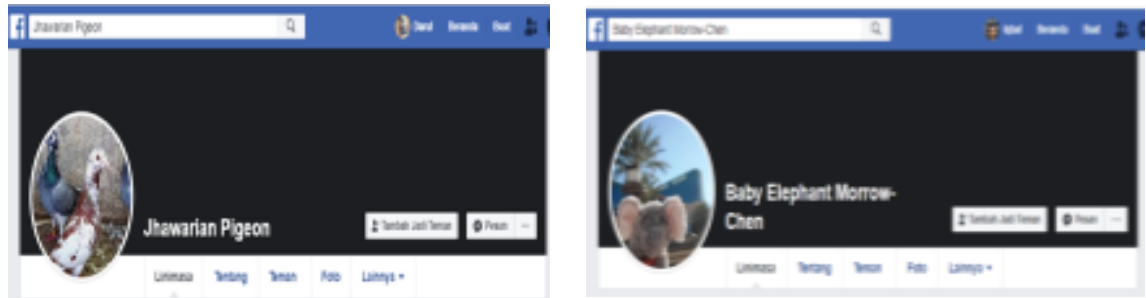

Facebook nicks like "Jhawarian Pigeon" and "Baby Elephant Morrow-Chen" are two of nickcs associated with animals. Pigeon is an animal which is well known with its loyalty and fidelity toward its mate, while Elephant is famus with its strength and community bond. Thus, by using the names of the animals in the Facebook nicks, the users might want not only to show to the public about the characters they wish to have but also to show to the public that they are loyal towards their fellows and strong to face their personal problems. They would create identity as gentle people with full of fidelity.

Occasionally, by using unique nicks in Facebook, a user might also want to show to the world that he/she exists. It might be used to show his/her existence identity which need to be recognized by others. In this study, a Facebook user uses directive word "here" to show the existence. "Tom Willhere" is a sample of the use of direction 'here' in Facebook nick.
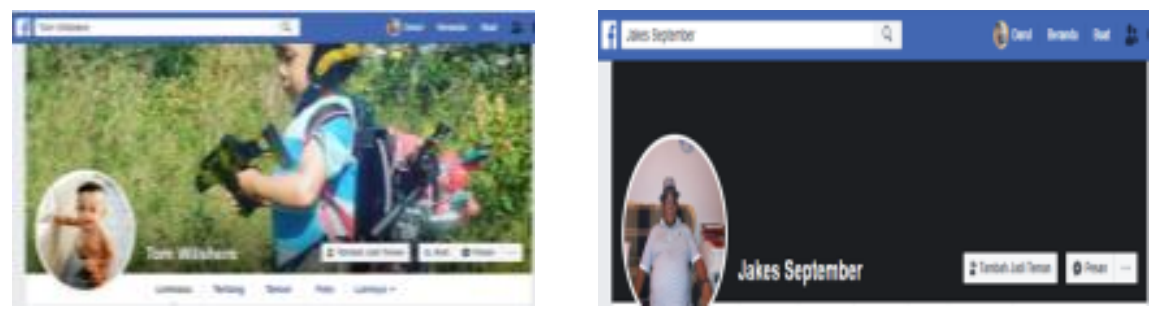

Moreover, sometimes a Facebook user wants his/her identity to be recognized through the time when he/she was born. Commonly, he/she uses a month of the year, such as August, September, etc. By attaching a month of the year, the user might associate it with the zodiac of the month. Commonly, zodiac such as Virgo, Cancer, Libra, etc is always labeled with certain characteristics. An example, "Jakes September", a Facebook nick, might be associated with Virgo zodiac. Virgo is characterized as introvert character. Indirectly, the user of "Jakes September' wants to create identity that he is an introvert person.

Data about an autolabelization associated with nobility in Facebook is also found. This autolabelization is in the form of the use of nobility titles such as "King," "Queen," "Princess" and the like. This style of labelization is used by both male and female Facebook users. Two examples, 'Queen Ashley Mello" and "King Benji", can be seen below.

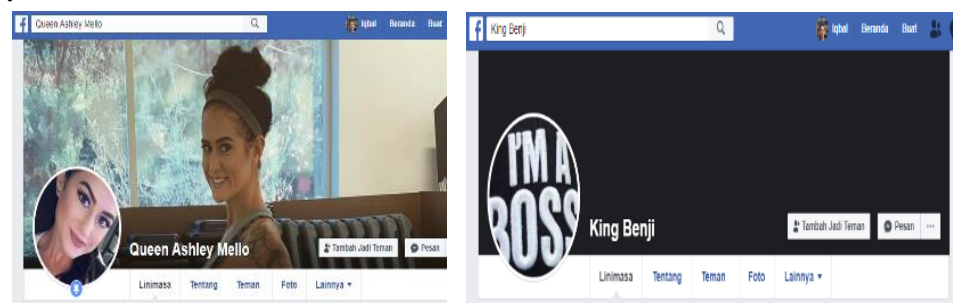

Long time ago, nobility titles such as "King," "Queen," and the like were not obtained easily. To get the title, someone had to be born from a noble family, or at 
least a ruler of a certain area. It is the so called ascribed status. On the other hand, the data of this study show the contrary. In the data, Facebookers get the King," and "Queen," title instantly only by writing it in the Facebook, whereas they do not belong to any of noble families in USA. They use the titles in order to put themselves in a higher place by using these sorts of nicknames. It seems that the titles are also like a wish that in the future, they could be like sorts of noble people with wealthy and superior characteristics.

The next type of autolabelization is the labalezation which is associated with instruments. Some instruments such as saxophone and guitar are used by Facebookers as the components of their Facebooks nicks. They mention the instruments as if the instruments are the part of their life.
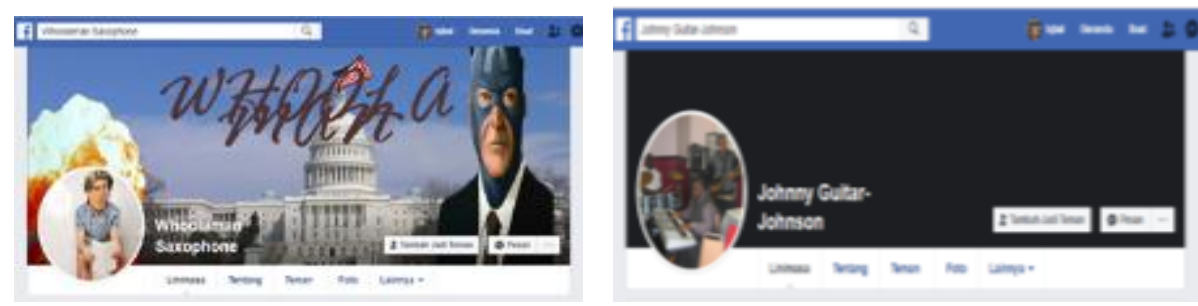

"Whoolman Saxophone' and "Jhonny Guitar-Jhonson" are two samples of Facebook nicks which use this way of labelization. It shows that the Facebokers are very close to these tools. In addition, the use of the instruments in their nicks show that they are very active in musical world especially in jazz music.
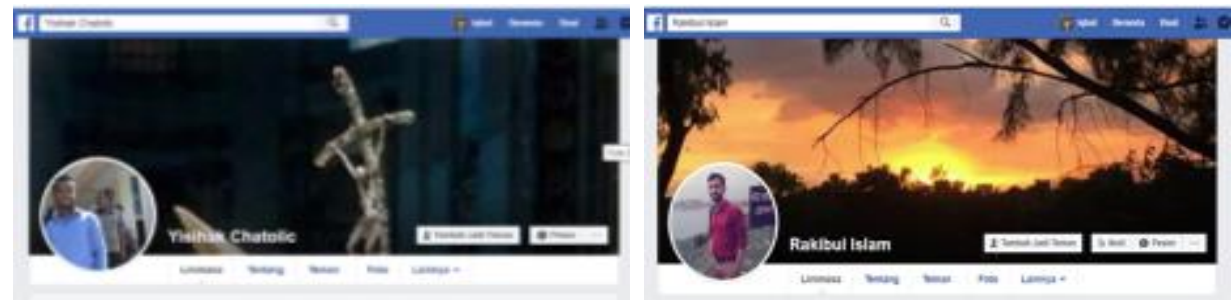

Some data also show that nicks of Facebook are also constructed by using some words which relate to religions matters. These terms are used to show the Facebookers' identity as certain religions worshipers. The words "Chatolic" and "Islam" are the words that appear in the data to be used by Facebookers as a part of their Facebook Nicks.

Two examples of Nicks which use some words which relate to religions matters can be found in the data. "Yisihak Chatolic" and "Rakibul Islam" are the Nicks that by only seeing the last name ("Catholic" and "Islam") the readers would be able to conclude to what religions they are affiliated with. Morover, the name "Yisihac" is also similar with the name of a prophet "Isaac" in Christianity, while the name "Rakibul" is clearly seen as taken from Arabic language. The two Facebookers chose the Nicks to show their admiration to the two religions ("Catholic" and "Islam").

Another type of autolabelization is found in the data. This type of labelization is associated with some physical appearances such as "handsome" and "pretty. The two physical conditions are used to label the Facebookers' prominent identity. This style can be found in "Chris Poyner (handsome)" and 'Pretty Jaylah." 

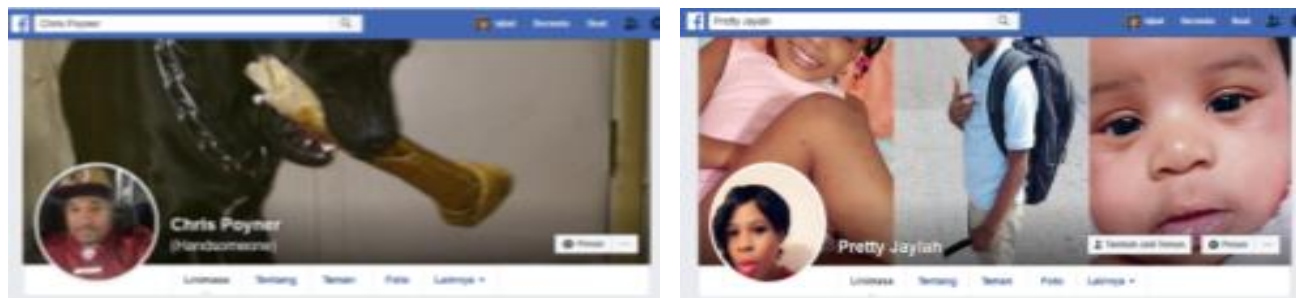

From the data above it can be seen two phenomena that Facebookers chose the Nicks for themselves by showing their perception on themselves. "Handsome" and "Pretty" are to positive words that refer to the quality of people's physical performance. By using the two words as the component of their nicks, it indicates that the Facebookers are quite confident with themselves and their appearance. This is a sign of self-confident and self-expectation. Sometimes, Facebookers are also known to use words that describe the quality of their body parts, such as the shape of the nose in Facebook Nick "Catherine Pug Nosy", the shape of the hair in Facebook Nick "Samantha Curly" and to show the body posture in Facebook Nick "Tall Jimmy.'

The next type of autolabelization is the labelization which is associated with occupations. In the data, it is found that some Facebookers chose Nicks which clearly inform their work affiliations to the others. This type of autolabelization can be seen in the nickname "Dante Lee "The Revenue Doctor" and "Otto the Director" See the following data.
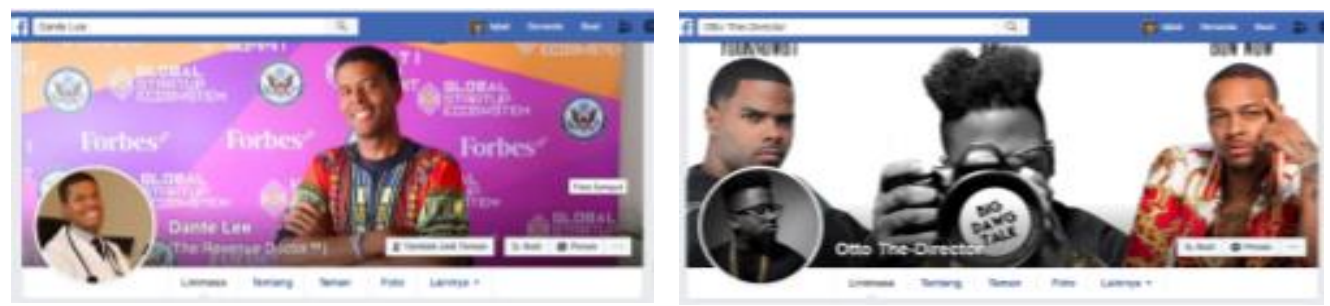

"Dante Lee "The Revenue Doctor" and "Otto the Director" are the Nicks that are clearly attached to occupations and the working fields. The word "Doctor" is closely connected to a Hospital or a Medical Center while "Director" is closely connected to a Movie company or an Entertainment Company.

In the data list, it is found that Nick can also be provocative since it is associated with a certain ideology. In the data list, there is one Facebook Nick that is considered to be provocative since it can make a person or a group of people be offended when reading the Nick. Nick "Sherman Anti-Trust Act" is the example of this kind of labelization. The word "Anti" somehow might bring inconvenient feeling since it is against a certain issue which is Trust Act. This Nick is clearly more visible to have ideological nuance hostility for mentioning an issue to be contradictory with. See the following datum.

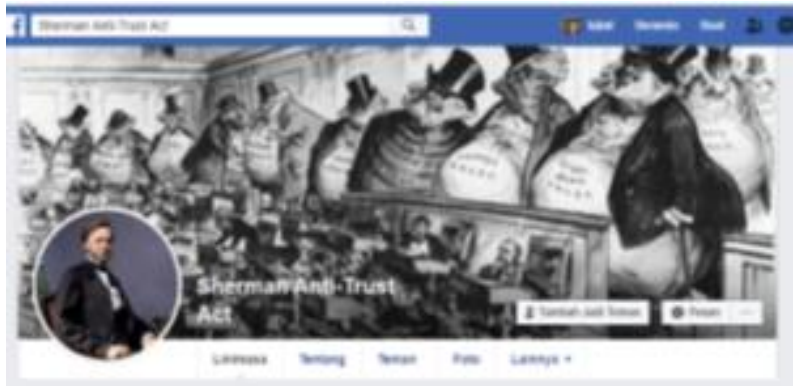


Facebook Nick is also found to include personal relationship status with another. That is why in this study, this kind of Nick style is categorized as an independent style which is called as Autolabelization associated with personal relation. A data is found to construct a Nick by adding someone's spouse name, for example by adding the name of a husband. Only a female Facebook user uses this style. This can be seen in the nickname "Gabriella Stepford Wife." The name of the person who is attached to the nick's user is her husband "Stepford". The husband's last name is placed on the back of Gabriella name to show the identity that they are married. See the following datum.

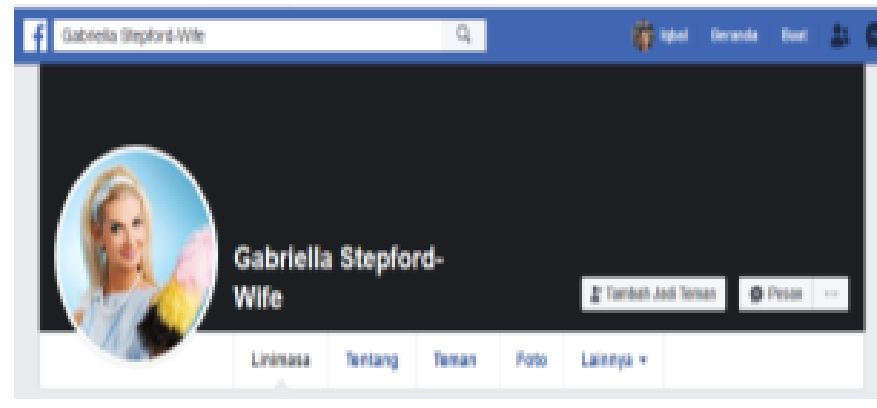

The last type of autolabelization is the labelization which is associated with sex and eroticism. From the list of data, it can be found that Facebooker Nick can also be "wild and naughty." A Word or a phrase that is related to sex and eroticism might be constructed by a Facebook user to be a part of his Nick. In this study, a Phrase "Pussy Fucker" was Chosen by a Facebookes to be his nick. Base on this phenomenon, it is assumed that the user chose the phrase since according to him the phrase looked eyecatching, and indicated openness and braveness. See the following datum.

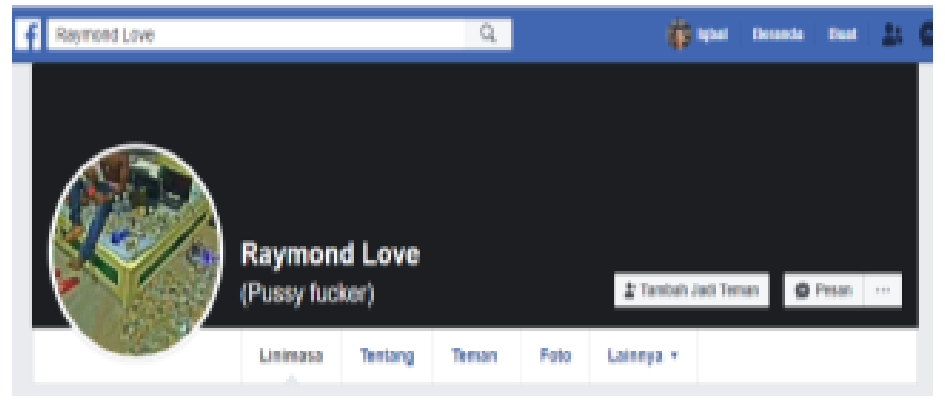

\section{A Banal Interpretation on the Representation behind Nicks Associations}

Sometimes lingual data not only represent lingual aspects such as sounds, words and meanings, but also represent the socio-cultural conditions in which the lingual data appear. As we all know, in earlier ages, to get a "sovereign" status such as "King" and "Queen" (as seen in the data above), it took effort that sometimes caused bloodshed. Long time ago, nobility titles such as "King," "Queen," and the like were not obtained easily. To get the title, someone had to be born from a noble family, or at least a ruler of a certain area. It is the so called ascribed status. Alternatively, one had to be able to prove one's courage, and advantage to others. If he/she was proven to have the characteristics needed to be a "King" and "Queen", then the community would inaugurate the title to him/her. The title obtained in this way is what is called as achieved title. 
Interestingly, from the relationship between the nicks and the users, it can be seen that there is unclear common thread between the nicks with the people who use thats nick in Facebook. Through the data obtained, it can be seen the presence of innovation in giving or using people's personal nicks. If in the past all titles used by people were caused by the process of being ascribed (hereditary) or by the process of achieving through strugles, then the present situations (in Facebook Nicks cases), the use of that titles are caused by people's wills. These phenomena are called as autolabelization.

Through Facebook, it can be seen that Facebookers have "licentia autolabelia" power (the great power to label themselves), because only by using a keypad of a smartphone, or keyboard of a laptop, the desire to be something (to passion to possess a certain identity) would easily be realized. "Be" then "an identity will truly be."

This great power sometimes causes problems in Facebook online community. Because users have the same unlimited power, the discretions between Facebook users are almost unavoidable. This is reason behind the emergence of public negative sentiment towards Facebook and other social media that they are the warehouses of social problems, mainly the problem of identity which is caused by language discretion.

This study also obtains the reasons why the processes of autolabelization emerge. Based on a deeper analysis on the factors that caused the informants to create unique nicks, it has been found five major factors. See the following table.

Table 2. The Factors to Create the Unique Nicks

\begin{tabular}{|c|l|c|}
\hline No & & $\begin{array}{c}\text { Frequency of } \\
\text { Appearance }\end{array}$ \\
\hline 1 & the desire of Facebookers to exist & 32 \\
\hline 2 & the reinforcement of Facebookers internal problems & 29 \\
\hline 3 & the desire to be bound to someone, or a group of people & 21 \\
\hline 4 & is the push of external problems & 17 \\
\hline 5 & the desire to be different & 1 \\
\hline & TOTAL DATA & 100 \\
\hline
\end{tabular}

The first reason is the desire of Facebookers to exist. The informants who mentioned the first reason usually had modern, up to date nicks. The second reason is the reinforcement of Facebookers internal problems. Internal problems sometimes also cause Facebookers to use particular nicks which represent their feelings like being angry, being hopeless, being lonely and so forth. Some informants also mentioned that they had introverted nature that made them feel ashamed to show their real names which according to them could be considered less modern. The third reason is the desire to be bound to someone, or a group of people. This is the reason why Facebookers used husband's name, idol's name and place of birth. The fourth reason is the push of external problems. There were some external problems that caused Facebookers to act reactively by using certain nicks as the response against external conditions that were not in accordance with their wishes. These responses were usually provocative and high-pitched, as the tone contains elements of disappointment and anger towards a person, group of people, or regulations in society. The fifth reason is the desire to be different. This desire is demonstrated through the selection of nicks that are different from other usual nicknames. Usually these nicks are in the form of slang words, sometimes dirty words. 
Having unlimited powers in online world to manipulate identity, sometimes brings problems that make authorities require extra energy to solve. The following is the list of the issues which can be summarized by this study related to personal autolabelization phenomena. 1) Asynchronous, the problem of different perspectives, because most of the nicks are not connected with the users. A Nick "I'm falling" may indicate a real fall, but it could be that the fall incident has occurred in the past and the user has not fallen again, 2) Nicks are selective self-representations which are caused by many users who camouflage themselves behind the nicks. Users sometimes hide paradoxical things behind the nick, which include hatred (negative) and love (positive) feelings, (3) Nick can cause fraud, because sometimes users use nicks as a disguised tool to commit crime.

\section{CONCLUSION}

Based on the discussions above, it can be concluded that Facebook nicks used by Facebookes might label their personal social identities. The autolabelization is associated with various things which include autolabelization associated with fictional character, places of origin, idols, symbol of kindness, feelings, animals, time of existence, nobility, instruments, religions, physical appearances, occupations, ideology, personal relation and sex and eroticism. Simply, each associated thing and person depicts socially different identities.

Due to the titling orientation change, the values that can be obtained when Facebookers use nicks have also disoriented. From this study, it can be concluded that Facebookers' nicks cannot only be assumed as egalitarian expressions; but also as pointers to expressions of personal dependencies that are intentionally created to shape particular wished characteristics that sometimes are difficult to explain, especially on how the nicks represent the users.

\section{REFERENCES}

Acquisti, A., Gross, R. and Stutzman, F., (2011) Privacy in the Age of Augmented Reality. In BlackHat USA Conference. Las Vegas, Nevada, 3-4 Augustus 2011.

Ashirova, G. A et.al (2016) Nicknames in Bashkir (Theoretical Aspects of Studying). Indian Journal of Science and Technology, Vol 9(27), DOI: 10.17485/ijst/2016/v9i27/97691, July ISSN (Print): 0974-6846. ISSN (Online) : 0974-5645

Boyd, D., (2010) Social Network Sites as Networked Publics: Affordances, Dynamics, and Implications. In: Z. Papacharissi, ed., 2010. Networked Self: Identity, Community, and Culture on Social Network Sites. pp. 39-58.

Boyd, d., (2011), August 4. "Real Names" Policies Are an Abuse of Power. [online] Available at: http://www.zephoria.org/thoughts/archives/2011/08/04/realnames.html Retrieved 8 February, 2019

Boyd, d., Hargittai, e., Schultz, J., and Palfrey, J., (2011) Why parents help their children lie to Facebook about age: Unintended consequences of the 'Children's Online Privacy Protection Act'. First Monday, 16 (11), [online] Available at: http://firstmonday.org/htbin/cgiwrap/bin/ojs/index.php/fm/article/viewArticle/3 850/3075 Retrieved 8 February, 2019 
De Koster, W., and Houtman, D., (2008) "Stormfront is like a second home to me": On virtual community formation by right-wing extremists. Information, Communication, \& Society,11, pp.1155-1176.

Ellison, N., R. Heino \& J. Gibbs (2006) Managing impressions online: Selfpresentation process in the online dating environment. Online-journal Journal of Computer- Mediated Communication. <http://jcmc.indiana.edu/vol11/issue2/ellison.html> Retrieved 8 February, 2019

Ellison, N. B., Hancock, J. T., and Toma, C., (2012) Profile as Promise: A Framework for Conceptualizing Veracity in Online Dating Self-Presentations. New Media \& Society 14(1), pp.45-62.

Ellison, N. Steinfield, C. and Lampe, C., (2007). The benefits of Facebook 'friends': Exploring the relationship between college students' use of online social networks and social capital. Journal of Computer-Mediated Communication, 12(3)

Ellison, N.B., Steinfield, C. and Lampe, C., (2011). Connection Strategies: Social capital implications of Facebook-enabled communication practices. New Media \& Society, 13(6), pp.873-892.

Gonibeed, A (2014) Exploring the Self-presentations of Indian IT Profssionals on SSocial Media. Doctoral Thesis. Loughborough University Institutional Repository.

Gonzales, A. L. and Hancock, J. T., (2011) "Mirror, Mirror on my Facebook Wall: Effects of Exposure to Facebook on Self-Esteem." Cyberpsychology, Behavior \& Social Networking, 14(1-2), pp.79-83.

Lev, E. \& A. Lewinsky (2004) The Presentation of Self in Online Life: The Importance of Nicknames in Online Environments. Powerpoint Presentation. <http://gsb.haifa.ac.il/ sheizaf/AOIR5/nameseimianat.ppt> Retrieved 8 February, 2019

Nakamura, L., (1999) Race In/For Cyberspace: Identity Tourism and Racial Passing on the Internet. dalam: V. Vitanza, ed., 1999. Cyberreader. Boston, MA: Allyn and Bacon.

Phillips, W., (2011) LOLing at tragedy: Facebook trolls, memorial pages and resistance to grief online. First Monday, 16(12), [online]

Reisinger, D., (2012). Facebook buys facial-recognition startup. C|NET, 19 June 2012, [online] http://asia.cnet.com/facebook-buys-facial-recognition-startup62216765.htm Retrieved 8 February, 2019

Scheidt, L. A. (2001) Avatars and Nicknames in Adolescent Chat Spaces. http://loisscheidt.com/working_papers_archive/Avatars_and_Nicknames.pdf. Retrieved 8 February, 2019

Starks, D \& Leech, K T. (----) A Research Project On Nicknames And Adolescent Identities. New Zealand Studies in Applied Linguistics 17 (2) 87 - 97. La Trobe University and University of Southern Queensland

Sundén, J., (2003) Material Virtualities. New York: Peter Lang.

Vitak, J., Lampe, C., Gray, R., and Ellison, N. B., (2012) "Why won't you be my Facebook Friend?": Strategies for managing context collapse in the workplace. Paper dipresentasikan di the iConference, Toronto, Ontario, Canada. 